\title{
BILIARY PAH METABOLITES IN FISH FROM THE HIGHLY IMPACTED GUANABARA BAY, IN SOUTHEASTERN BRAZIL, DETERMINED BY FIXED AND SYNCHRONOUS FLUORESCENCE SPECTROSCOPY
}

\author{
Marina Moreira Freire ${ }^{\mathrm{a}, \mathrm{b}}$, Cristina Gómez ${ }^{\mathrm{e}}$, Anabela Sousa Oliveira ${ }^{\mathrm{c}, \mathrm{d} \dagger}$, Josino Costa Moreira ${ }^{\mathrm{a}}$ and Ana Rosa Linde

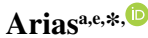 \\ ${ }^{a}$ Centro de Estudos da Saúde do Trabalhador e Ecologia Humana, Escola Nacional de Saúde Pública - Fundação Oswaldo Cruz, \\ 21041-210 Rio de Janeiro - RJ, Brasil \\ ${ }^{b}$ Universidade Federal Fluminense, 24020150 Niterói - RJ, Brasil \\ ${ }^{c}$ Centro de Química-Física Molecular e Instituto de Nanociência e Nanotecnologia, Instituto Superior Técnico, Universidade \\ Técnica de Lisboa, 1049-001 Lisboa, Portugal \\ ${ }^{d}$ Centro Interdisciplinar de Investigação e Inovação, Escola Superior de Tecnologia e Gestão de Portalegre, Instituto Politécnico \\ de Portalegre, 7301-901 Portalegre, Portugal \\ eEscola de Matemática Aplicada, Fundação Getulio Vargas, 22250-900 Rio de Janeiro - RJ, Brasil
}

Recebido em 04/05/2021; aceito em 27/08/2021; publicado na web em 22/09/2021

\begin{abstract}
Guanabara Bay (GB) covers the metropolitan region of the state of Rio de Janeiro in Brazil. GB is subject to heavy contamination by polycyclic aromatic hydrocarbons (PAHs), from intense oil activities, which pose an ecotoxicological threat. The aim of this study is to implement and optimize a fluorescence methodology for the determination of biliary PAH metabolites in fish species (burrfish and whitemouth croaker), in order to evaluate biliary PAH metabolites as a biomarker of exposure. Fish were sampled from GB and a control region. Naphthalene, pyrene and benzo(a)pyrene metabolites were determined by Fixed Fluorescence Method (FF), while 1-hydroxypyrene was assessed by Synchronous Fluorescence Spectroscopy (SFS). The implementation and optimization of the FF and SFS methods allowed the determination and evaluation of the exposure of these species to PAHs of pyrogenic and petrogenic origin. Biliary PAH metabolite determinations was proven to be a useful tool for environmental monitoring contamination assessments.
\end{abstract}

Keywords: PAHs; fish; biomarkers; aquatic pollution; bile metabolites.

\section{INTRODUCTION}

Aquatic ecosystems have been suffering the impact of contamination by Polycyclic Aromatic Hydrocarbons (PAHs). Guanabara Bay is located in the metropolitan region of the state of Rio de Janeiro in Brazil and is subject to heavy contamination by polycyclic aromatic hydrocarbons (PAHs) from intense oil activities, representing a threat to aquatic life. ${ }^{1}$ Guanabara Bay has a contamination profile that mixes pyrogenic and petrogenic sources of PAHs. High concentrations of carcinogenic PAHs, such as benzo(a)pyrene and naphthalene, were observed in a study on the characterization and distribution of PAHs in GB sediments., The coastal region of Itaipu is located on the oceanic edge of the municipality of Niterói. It is considered a well-preserved area, although the intense urbanization with tourism has caused changes in its physical, chemical and biological attributes. ${ }^{4}$

PAHs are a major source of contamination in aquatic ecosystems, as they are ubiquitous in all environmental compartments ${ }^{5}$ and toxic to aquatic organisms. ${ }^{6} \mathrm{PAH}$ sources can be natural or anthropogenic. ${ }^{7}$ PAHs reach aquatic environments in different ways, including atmospheric deposition, surface rain runoff, wastewaters, industrial effluents, petroleum spills, etc., ${ }^{8}$ and are usually found as complex mixtures in the environment, as they are not individually released. ${ }^{9}$

PAHs are a large class of organic compounds containing two or more condensed aromatic rings ${ }^{10}$ which can have pyrogenic, petrogenic, diagenic or biogenic origins. ${ }^{9,11}$ These compounds are solid at room temperature, displaying low water solubility, that

*e-mail: linde14@yahoo.com

in memoriam usually decreases with increasing amounts of condensed aromatic rings in the structure, i.e., with increased molecular weight. ${ }^{7}$ Although PAHs present similar chemical structures, their physico-chemical properties are significantly variable. For example, PAHs containing up to three aromatic rings are termed low molecular weight (LMW) PAHs, while those with over three aromatic rings are named high molecular weight (HMW) PAHs, with each group presenting similar characteristics. In fact, molecular weight differences greatly determine physico-chemical PAH properties. ${ }^{12}$ For instance, LMW PAHs present low boiling and fusion points, as well as low octanol/ water partition coefficients $\left(\mathrm{K}_{\mathrm{ow}}\right)$, exhibiting a certain amount of water solubility, increasing their degradability, and displaying higher vapour pressure in comparison to HMW PAHs. HMW PAHs, on the other hand, present high boiling and fusion points, low water solubility, higher $\mathrm{K}_{\mathrm{ow}}$ and display high toxicity to both plants and animals..$^{12,13}$ As $\mathrm{K}_{\mathrm{ow}}$ translates to the organic/aqueous partition trend of organic compounds, this parameter has been related to PAH bioconcentration in living organisms, since it simulates the partition between water and fatty tissues. ${ }^{14,15}$ Table 1 present selected relevant physico-chemical $\mathrm{PAH}$ properties in water.

The most relevant water PAH degradation processes are photooxidation, chemical oxidation and biodegradation by aquatic organisms, hydrolysis is not considered relevant to PAH degradation.

PAHs are considered priority pollutants for environmental monitoring by the United States Environmental Protection Agency (USEPA), as they pose significant risks to human and ecosystem health and integrity. ${ }^{16,17}$ Furthermore, some PAHs are classified by the International Agency for the study of Cancer (IARC) as carcinogenic, mutagenic and/or genotoxic. ${ }^{8,14}$ Several studies have been carried out to evaluate the link between PAH-contaminated environments and the 
Tabela 1. Physicochemical properties for Naphthalene, Pyrene, 1-Hydroxypyrene and Benzo(a)pyrene ${ }^{7,13}[3,10]$

\begin{tabular}{ccccccc}
\hline No. of benzenic rings & PAH & $\begin{array}{c}\text { Molecular weight } \\
\left(\mathrm{g} \mathrm{mol}^{-1}\right)\end{array}$ & $\begin{array}{c}\text { Vapour pressure } \\
\left(\mathrm{Pa}, 25^{\circ} \mathrm{C}\right)\end{array}$ & Log Kow & \multicolumn{2}{c}{$\begin{array}{c}\text { Water solubility } \\
\left(\mathrm{mg} \mathrm{L}^{-1}\right)\end{array}$} \\
\hline $\mathbf{2}$ & Naphthalene & 128 & 36.4 & 3.37 & 31 & $\begin{array}{c}\text { Half-life in water } \\
(\mathrm{h})\end{array}$ \\
$\mathbf{4}$ & Pyrene & 202 & 0.0119 & 5.18 & 0.132 & 170 \\
$\mathbf{4}$ & 1-Hydroxypyrene & 218 & $3.89 \times 10^{-6}$ & 4.6 & 3.5 & 1700 \\
$\mathbf{6}$ & Benzo(a)pyrene & 252 & $2.13 \times 10^{-5}$ & 6.04 & 0.0038 & 1700 \\
\hline
\end{tabular}

development of hepatic diseases, including neoplasies in aquatic biota, such as fish. ${ }^{18-21}$ Although acute PAH toxicity is relatively low, possible adverse effects observed in PAH-exposed fish due to chronic toxicity are frequent. ${ }^{22}$ Sublethal effects include the formation of DNA and RNA adducts, necrosis, mortality in different developmental stages, decreased growth, immunosuppression, different deformities, spine injuries, cataracts and tumours, among others. ${ }^{9,22}$ Due to the severe effects resulting from $\mathrm{PAH}$ exposure, concerns regarding their impacts in aquatic ecosystems have been noted, evidencing the need for their environmental monitoring to assess their effects in these environments.

PAH analyses in sediment and surface waters, as well as in costal and estuarial waters, have been carried out year round, providing important information on environmental PAH levels and sources. ${ }^{6}$ However, these data do not provide information on the effects of these substances on living organisms. Environmental monitoring based exclusively on the chemical analysis of sediments and waters is, thus, inappropriate for PAH contamination effect evaluations and predictions. ${ }^{23}$ Thus, in order to evaluate the impact of these pollutants on ecosystem quality, living organism exposure assessments to stressor substances are required. ${ }^{24}$

An appropriate group of biological responses can be useful to evaluate the level of stressor or pollutant impacts on biota health. ${ }^{25}$ Biomarkers can detect PAH/PAH metabolite exposure and/or toxic effects. These compounds and their metabolites are, in some cases, rapidly metabolized and eliminated by organisms, ${ }^{26}$ where the main metabolic organ is the liver, while the gallbladder is the main storage pathway, until excretion. The presence of PAH metabolites in fish bile is, therefore, a risk factor for species exposed to this class of compounds, and biliary PAH metabolite analyses comprises an excellent exposure biomarker in which can be widely applied in environmental monitoring programs. ${ }^{27}$

Biliary PAH metabolite detection in fish has been routinely applied to monitor exposure to these compounds..$^{21,28-31}$ Metabolite analyses are commonly based on the PAH fluorescence determination, ${ }^{10}$ as PAHs are strong fluorophores, due to the rigidity of their aromatic structure, presenting delocalized p-electrons throughout their entire molecular structure. . $^{10,32,33}$

For PAH absorption to occur from the ground $S_{0}$ state to the $S_{1}$ or $S_{2}$ excited states, the absorbed energy has to be higher or equal to the energy difference between the $S_{0}$, ground state, and the $S_{1}$, excited state. This is a constant value, characteristic of the molecular structure of each PAH, and corresponds to the maximum absorption wavelength of the PAH absorption spectra. This wavelength can be used as an excitation wavelength $\left(\lambda_{\text {exc }}\right)$, in order to obtain the fluorescence emission spectra of a certain PAH. The excited molecule then returns to its ground $\mathrm{S}_{0}$ state emitting light, i.e. fluorescence. The maximum energy of this emission occurs at the maximum emission wavelength $\left(\lambda_{\mathrm{em}}\right)$ of the fluorescence spectra and is also characteristic of the molecular structure of each compound.$^{34,35}$ During emission, part of the absorbed energy is lost as heat (non-radiative emission from $\mathrm{S}_{2}$ to $S_{1}$ ), the fluorescence emission energy (from $S_{1}$ to $S_{0}$ ) is lower than the excitation energy of the PAH (at least the one corresponding to the $S_{0}$ to $S_{1}$ transition). ${ }^{36}$ This energy difference, between excitation $\left(\lambda_{\text {exc }}\right)$ and emission $\left(\lambda_{\text {em }}\right)$ wavelengths is called the Stokes shift and is frequently used as the appropriate wavelength difference $(\Delta \lambda)$ in synchronous fluorescence spectroscopy. ${ }^{10}$

Excitation and emission properties are constant for a given measuring instrument, environmental experiment conditions and substance characteristics, and can be used to identify and quantify certain fluorescent compounds. ${ }^{36}$ Because of this, biliary PAH fluorescence has been applied to assess aquatic ecosystem contamination by these compounds. ${ }^{10}$ Bile fluorescence can be evaluated either using fixed excitation wavelength or synchronous fluorescence through the simultaneous scanning of excitation and emission wavelengths. ${ }^{10}$

Although biliary PAH fluorescence can be investigated through several analytical techniques, quick and low-cost methods are essential for environmental monitoring. In 1987, Krahn et al. introduced high performance liquid chromatography (HPLC) for biliary fish PAH metabolite determination. ${ }^{37}$ Subsequently, Lin et al., in 1996, compared the use of HPLC and fixed excitation wavelength fluorescence (FF) to determine benzo(a)Pyrene and Naphthalene metabolites in this matrix ${ }^{38}$ and, in 1997, Ariese et al. compared synchronous fluorescence spectroscopy (SFS) and HPLC for PAH metabolites analyses in flounder bile exposed to contaminated sediments in a mesocosm.$^{39}$ In 2000, Aas et al. applied the FF method to determine PAH metabolites in fish bile. ${ }^{30}$

FF and SFS are noteworthy among the various methods used to evaluate PAH exposure. ${ }^{10}$ Both are semi-quantitative as, for any given wavelength, fluorescence contributions arising from other fluorescent compounds are possible, in addition to from the assessed PAH metabolite. Although both methods do not allow for the identification and determination of specific PAH metabolites, a criterious and careful choice of excitation and emission wavelength pairs allows for high selectivity for certain compounds. ${ }^{10}$ In fact, fluorescent compounds that emit in the same pair of absorption and emission wavelengths generally include the target PAHs and their metabolites, the alkyl derivatives of the PAH and their metabolites, as well as nitrogen $(\mathrm{N})$, sulphur $(\mathrm{S})$ and oxygen $(\mathrm{O})$-containing compounds that possess identical molecular structures to the assessed PAH. ${ }^{40}$

FF involves the selection of PAH metabolites using fixed and characteristic excitation and emission wavelength pairs of a given compound, ${ }^{41}$ while SFS analyses metabolites by simultaneously scanning excitation and emission wavelengths (and monochromators), therefore increasing selectivity. ${ }^{39}$ Both are quick, due to the simplicity of the sample preparation process and short analysis time, allowing for the analysis of a high number of samples. This is extremely important in field analyses, where biological variability of organisms is usually high. Furthermore, both are low-cost techniques and display high selectivity, enabling for the distinction between exposed and non-exposed fish. ${ }^{10}$

In this context, the aim of this study was to implement and optimize a fluorescence methodology for the determination of biliary PAH metabolites in two fish species (burrfish and whitemouth croaker) as a PAH exposure biomarker at Guanabara Bay, Rio de Janeiro, Brazil. 


\section{MATERIAL AND METHODS}

\section{Reagents}

Naphtalene (AccuStandard), Pyrene (Sigma Aldrich), 1-Hydroxy-Pyrene (Sigma Aldrich) and Benzo(a)Pyrene (Sigma Aldrich) were used as standards, displayed in Scheme 1. Naphthalene has a petrogenic origin and Pyrene and benzo(a) Pyrene are pyrogenic. ${ }^{38}$

Ethanol (HPLC grade, 99,9\% from Merck) and ultrapure water were used for sample preparation.

\section{Equipment}

An LS 45 Perkin Elmer spectrofluorometer (transmission geometry operation; equipped with a sample holder for $1 \mathrm{~cm}$ cells, fixed $10 \mathrm{~nm}$ slits and spectral acquisition from $200 \mathrm{~nm}$ to $650 \mathrm{~nm}$ ). This spectrofluorometer allows for the determination of three types of spectra: Fluorescence Emission (scan wavelength analysis to a fixed wavelength excitation); Synchronized Fluorescence Emission (simultaneous scan of the excitation monochromators and analysis, at a fixed wavelength difference, $\Delta \lambda$, which usually translates the difference in wavelengths between the maximum of the excitation spectrum or absorption, and fluorescence), and Excitation (scan wavelength analysis to a fixed wavelength excitation) spectra.

The spectrofluorometer was calibrated with certified Naphthalene and rhodamine standards (Perkin Elmer). Measurements were performed with $1 \mathrm{~cm}$ quartz cuvettes (Perkin Elmer).

In addition, a digital Marte scale with three decimals and/or Mettler analytical balance brand with four decimals, a Bransons sonication water bath and a Phoenix pipe stirrer were also used.

\section{Bile sampling and extraction}

Burrfish and whitemouth croaker were collected monthly from May to December 2007 at Guanabara Bay (GB) and Itaipu. A total of 173 burrfish and 116 croakers were collected. Of the 173 burrfish collected, 92 were captured in GB and 81 in Itaipu. Regarding croakers, 62 specimens were collected at GB and 54 at Itaipu. After sampling, the fish were taken, on ice, to the Ecotoxicology Occupational Health Center and Human Ecology Laboratory (CESTEH), belonging to the Oswaldo Cruz Foundation. Gallbladders were immediately extracted and stored in Eppendorf ${ }^{\circledR}$ tubes at $-20^{\circ} \mathrm{C}$, the optimum temperature to maintain sample stability until analysis. ${ }^{42}$ Bile metabolite determinations were carried out up to one week after extraction, after thawing the bile samples in an ice bath.

\section{PAH selection for fish exposure evaluation}

To evaluate fish exposure, 2-, 4- and 6-ringed PAH metabolites were analyzed, namely naphthalene-, pyrene- and benzo(a)pyrene-type metabolites, respectively. Furthermore, the major pyrene metabolite, 1- hydroxypyrene, ${ }^{30,43}$ was also analyzed. These metabolites were chosen because they represent PAHs from both a petrogenic origin, such as naphthalene, and pyrogenic origin, like as pyrene and benzo(a)pyrene..$^{38}$ In addition, these metabolites have already been assessed in previous studies conducting environmental contamination biomonitoring efforts through fish bile fluorescence. ${ }^{29,30,38,44}$

\section{PAH standard solutions}

Appropriate amounts of naphthalene, pyrene, benzo(a)pyrene and 1-hydroxypyrene standards were weighed on an analytical balance and diluted with ethanol for standard PAH solution preparations. Ethanol is commonly used in fish bile PAHs determinations, and is easy to purchase and is relatively cheap. ${ }^{5,10,30,43}$ After PAH solubilization, ultrapure water was added, in order to obtain an ethanol/water $(50: 50 \mathrm{v} / \mathrm{v})$ mixture, considered by Ariese as presenting the appropriate polarity to solubilize all bile components, resulting in clear samples. ${ }^{43}$

\section{Excitation and emission wavelength determinations}

Prior to fish bile analyses, the ideal excitation $\left(\lambda_{\text {exc }}\right)$ and emission $\left(\lambda_{\mathrm{em}}\right)$ wavelengths for PAH metabolite assessments were determined, by evaluating naphthalene pyrene, benzo(a)pyrene and 1-hydroxypyrene standard solutions. Concentrations previously tested by spectrofluorometry and within the equipment range were chosen. After preparation, standard solution fluorescence intensities were determined. All solutions were maintained in the dark until analysis, to avoid PAH degradation. Common fluorescence emission spectra and synchronous fluorescence emission spectra, ${ }^{33,35}$ were determined, termed Fixed Fluorescence (FF) (applying a fixed excitation wavelength) and synchronized fluorescence spectroscopy (SFS)..$^{30,43,45}$

Prior to the analyses, the equipment was calibrated using commercial naphthalene and rhodamine standards certified by Perkin Elmer, to ensure adequate and identical analysis conditions every day.

For optimal wavelength pair selection $\left(\lambda_{\mathrm{exc}}\right.$ and $\left.\lambda_{\mathrm{em}}\right)$, standard naphthalene, pyrene, benzo(a)pyrene solutions were scanned by FF. Briefly, the $\lambda_{\text {exc }}$ of each standard was set at $200 \mathrm{~nm}$ and the $\lambda_{\text {em }}$ scan was set from 220 to $600 \mathrm{~nm}$. After this first reading, the $\lambda_{\text {exc }}$ was set at $220 \mathrm{~nm}$ and rescanned from 240 to $600 \mathrm{~nm}$. This was performed several times, varying the $\lambda_{\text {exc }}$ from 20 to $20 \mathrm{~nm}$. After this step, the maximum $\lambda_{\text {em }}$ were obtained and the optimum emission wavelength of each compound (maximum fluorescence emission band) was evaluated. Thus, the best excitation wavelength (which achieves the greatest fluorescence intensity at the maximum wavelength of the fluorescence emission band) was elected for each compound.

To determine the optimal parameters for the 1-hydroxypyrene analysis by SFS, standard solution scans performed from 200 to $600 \mathrm{~nm}$, with $\Delta \lambda$ of 37,45 and $52 \mathrm{~nm}$. These $\Delta \lambda$ have been recommended by other authors in similar studies. ${ }^{29,37}$ The ideal $\Delta \lambda$ and synchronous fluorescence wavelength for 1-hydroxypyrene was, therefore, selected.

\section{Standard calibration curves}

Calibration curves for the four compounds were prepared from a series of dilutions of a standard solution for each, prepared on the analysis day. Serial dilutions were prepared with ethanol/water 50:50 (v/v) for each of the standards. The concentrations used to determine each of the four calibrations curves varied according to the determination range for each of the assessed PAHs. Thus, naphthalene dilutions were prepared at concentrations ranging from $1.3 \mu \mathrm{g} \mathrm{L}{ }^{-1}$ to $38.4 \mu \mathrm{g} \mathrm{L}^{-1}$, pyrene from $0.2 \mu \mathrm{g} \mathrm{L}^{-1}$ to $10 \mu \mathrm{g} \mathrm{L} \mathrm{L}^{-1}$, benzo(a) pyrene from $0.25 \mu \mathrm{g} \mathrm{L}^{-1}$ to $20 \mu \mathrm{g} \mathrm{L}^{-1}$, and 1-hydroxypyrene from $0.1 \mu \mathrm{g} \mathrm{\textrm {L } ^ { - 1 }}$ to $2.6 \mu \mathrm{g} \mathrm{L}^{-1}$. Different dilutions of each standard were evaluated by FF for naphthalene, pyrene and benzo(a)pyrene and SFS for 1-hydroxypyrene. The choice of the fluorescence analysis methodology was based on previously published studies. ${ }^{10,27,42}$ Calibration curves were repeated at least three times on different days and the final equations of the line were obtained from the concentration averages of each different analysis. 


\section{Fish bile standard addition study}

\section{Standard addition}

The standard addition method was applied to verify if the predetermined wavelengths were ideal for the determination of biliary PAH metabolites, where a standard solution of each of the four investigated $\mathrm{PAH}$, at different concentrations, was to fish bile samples.

Burrfish and whitemouth croaker bile samples were randomly chosen and prepared for conventional analysis, i.e, thawing followed by 15 minutes sonication and dilution with ethanol/water $(50: 50, \mathrm{v} / \mathrm{v})$. The prepared bile samples were analyzed at the preselected excitation and emission wavelengths by FF for naphthalene, pyrene and benzo(a)pyrene and by SFS 1-hydroxypyrene. After this step, a standard naphthalene solution at $1.3 \mu \mathrm{g} \mathrm{L}^{-1}$ was added to the samples and analyses were performed at the previously determined excitation and emission wavelength pairs. After this reading, a new naphthalene concentration was added and another analysis was performed, followed by a new standard addition and reading. The same experimental rationale was followed for pyrene, benzo(a)pyrene and 1-hydroxypyrene.

\section{Wavelength specificity evaluation}

Another series of experiments was performed to evaluate if the fluorescence of the four HPAs metabolites would influence the fluorescence reading of other compounds. Another set of bile sample was randomly chosen, prepared and analyzed conventionally, by assessing the presence of naphthalene, pyrene and benzo(a)pyrene metabolites by FF and 1-hydroxypyrene by SFS.

After the analyses, a standard naphthalene solution at $1.3 \mu \mathrm{g} \mathrm{L}^{-1}$ was added to the samples, which were then analyzed at the characteristic wavelengths of all the assessed PAH (naphthalene, pyrene, benzo(a) pyrene and 1-hydroxypyrene). Two other naphthalene concentrations were added sequentially, and new determinations were made.

This was performed for all assessed PAHs.

\section{Bile sample preparation and PAH metabolite determination in burrfish and whitemouth croaker}

Bile samples were thawed, sonicated for 15 minutes and diluted in ethanol/water (50:50, v/v). Subsequently, the samples were diluted 1,000-fold for pyrene and benzo(a)pyrene and 1-hydroxypyrene determinations. For naphthalene, a 5,000 dilution was applied to most samples, and a 10,000-fold dilution was required in some cases, due to high metabolite concentrations.

Bile dilutions were required not only to maintain fluorescence intensity within the measurement range of the equipment, but also to prevent matrix effects. This effect comprises cuvette light absorption during fluorescence measurements, by other sample constituents in bile sample other than PAHs. ${ }^{27}$

Recent studies by other authors have indicate that the dilutions applied herein are adequate and sufficient to prevent the matrix effect. Thus, no further tests related to this parameter were carried out. ${ }^{13}$

Measurements of each bile sample were then performed for all excitation and emission wavelengths pairs, as defined above, by FF and SFS. For each emission spectrum, the fluorescence intensity was measured at the $\lambda_{\text {em }}$ of each compound, previously chosen by assessing the PAH standards, corresponding to the maximum fluorescence emission band of each compound. The results were expressed as arbitrary fluorescence intensity units.

After obtaining the standard curves for each PAH, PAH bile metabolite concentrations from the fluorescence intensities at the $\lambda_{\mathrm{em}}$ of each compound were calculated. Since both applied methods are semi-quantitative, bile metabolite concentrations were expressed as equivalents of their respective standards PAHs, as follows: naphthalene-, pyrene-, benzo(a)pyrene- and 1- hydroxypyrene-equivalents.

\section{RESULTS AND DISCUSSION}

\section{Analytical parameters for PAH determinations}

\section{Excitation and emission wavelength determinations}

The determination of the excitation $\left(\lambda_{\text {exc }}\right)$ and emission $\left(\lambda_{\text {em }}\right)$ wavelength pairs for PAH metabolite evaluation by FF and the choice of $\Delta \lambda$ used in SFS are paramount in PAH metabolite determination implementation and optimization as, although these parameters are inherent to the assessed compounds, they may vary according to equipment properties and analytical conditions.

The ideal excitation $\left(\lambda_{\text {exc }}\right)$ /emission $\left(\lambda_{\text {em }}\right)$ wavelength pairs for naphthalene, pyrene and benzo(a)pyrene metabolites were $270 / 335 \mathrm{~nm}, 340 / 390 \mathrm{~nm}, 380 / 430 \mathrm{~nm}$, respectively (Figure 1), corresponding to their maximum excitation and emission intensities by FF, similar to wavelengths applied in other environmental monitoring studies applying the same technique $(290 / 335 \mathrm{~nm}$, $341 / 383 \mathrm{~nm}$ and 380/430 nm, respectively, for naphthalene, pyrene and benzo(a)pyrene bile metabolites, respectively). ${ }^{27,30,38}$

Regarding the SFS analysis of 1-hydroxypyrene, an $\Delta \lambda$ of $37 \mathrm{~nm}$ was chosen, as this wavelength resulted in narrower spectra, leading to increased selectivity for this metabolite when compared to the other tested $\Delta \lambda$ ( 45 and $52 \mathrm{~nm}$, respectively), in agreement with other literature reports, i.e. Ariese et al. (1993) when assessing PAH-contaminated sediment-exposed flounder (Platichthys flesus). ${ }^{43}$ Figure 1-D displays the 1-hydroxypyrene synchronous fluorescence spectra peaks obtained at $350 \mathrm{~nm}$.

\section{Standard curves}

Figure 2 presents the fluorescence spectra for the evaluated standard naphthalene, pyrene and benzo(a)Pyrene solutions and the 1-hydroxypyrene synchronous fluorescence spectra. PAHs calibration curves were calculated by determining the maximum intensity fluorescence at the previously selected emission wavelengths. The analytical parameters of the standard calibration curves alongside their equations and correlation coefficient $\left(\mathrm{r}^{2}\right)$ are presented in Table 2.

Standard naphthalene, pyrene, benzo(a)pyrene and 1-hydroxypyrene curves were prepared to adjust for the analytical parameters of biliary PAH metabolite determination. The standard curves were used to obtain the linear equations of the line ( $y=a x$ $+\mathrm{b}$ ) for the four compounds and their corresponding fluorescence intensities. Satisfactory $(>0.99)$ correlation coefficients $\left(r^{2}\right)$ were achieved, indicating linearity for the applied determination ranges.

\section{Standard addition effect assessments}

\section{Standard addition in bile}

The standard addition method was applied in order to verify if the wavelength pairs chosen using the PAH standards were ideal for biliary PAH metabolite determinations, as the bile matrix may lead to alterations in the previously determined PAH metabolite detection wavelengths. The results indicate that the peak wavelengths were the same than those obtained for the PAH standards, with no spectra displacement (Figure 3), (respectively 270/335, 340/390, 380/430 nm for naphthalene, pyrene and benzo(a)pyrene, as determined by FF; $\lambda_{\mathrm{em}}=350 \mathrm{~nm}$ and $\Delta \lambda=37 \mathrm{~nm}$ for 1-hydroxypyrene measured, as determined SFS). 


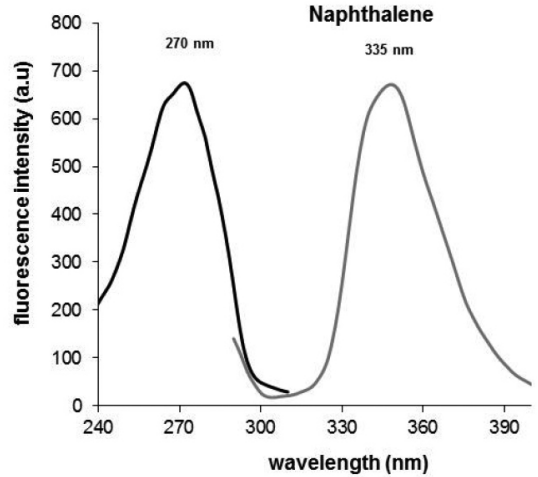
-Excitation spectrum

Benzo(a)pyrene

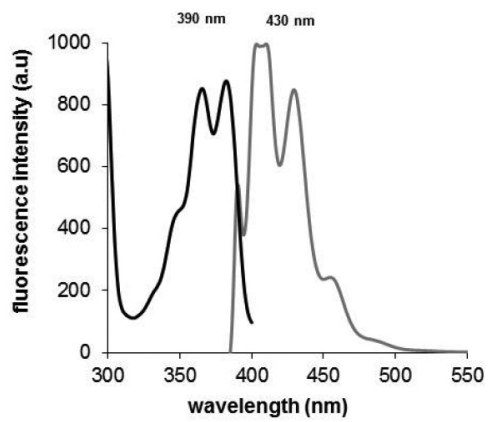

(A)

(C)

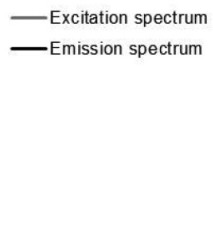

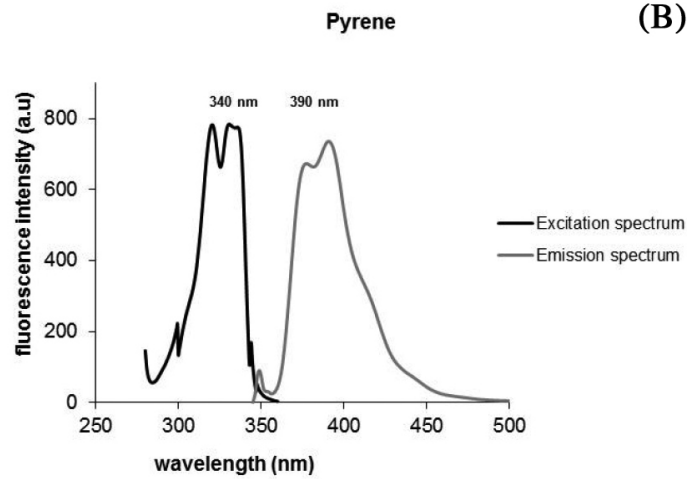

(B)

1- hydroxypyrene
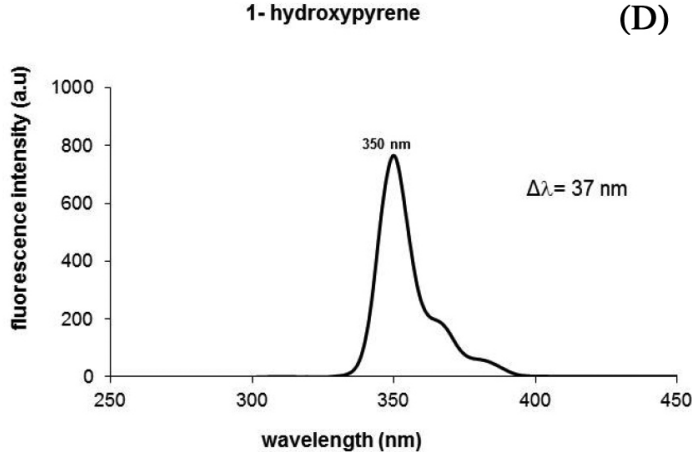

Figure 1. Excitation and emission spectra: A. Naphthalene excitation $\left(\lambda_{\text {exc }}=270 \mathrm{~nm}\right)$ and emission $\left(\lambda_{e m}=335 \mathrm{~nm}\right)$; B. Pyrene excitation $\left(\lambda_{\text {exc }}=340 \mathrm{~nm}\right)$ and emission $\left(\lambda_{e m}=390 \mathrm{~nm}\right) ; \boldsymbol{C}$. Benzo(a)pyrene excitation $\left(\lambda_{\text {exc }}=380 \mathrm{~nm}\right)$ and emission $\left(\lambda_{e m}=430 \mathrm{~nm}\right) ; \boldsymbol{D} .1-$ hydroxypyrene synchronous fluorescence spectra, $\Delta \lambda=37 \mathrm{~nm}$

Naphthalene

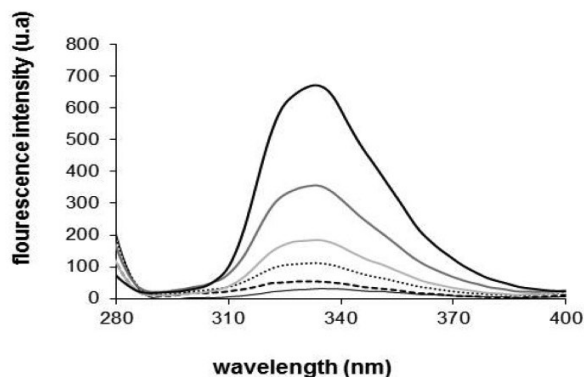

Benzo(a)pyrene

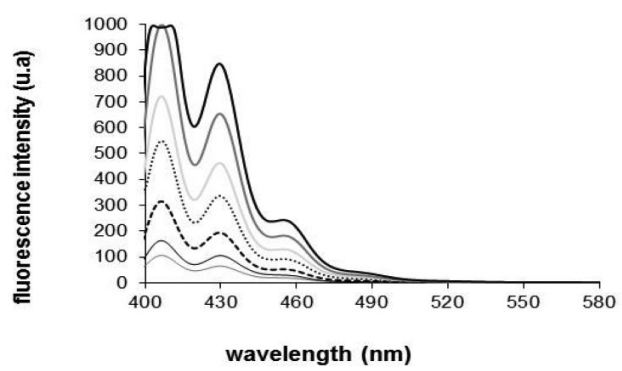

(A)

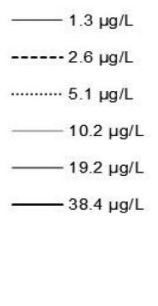

(C)

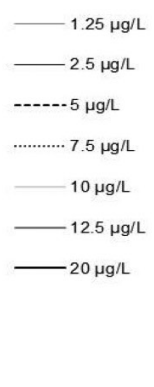

Pyrene

(B)

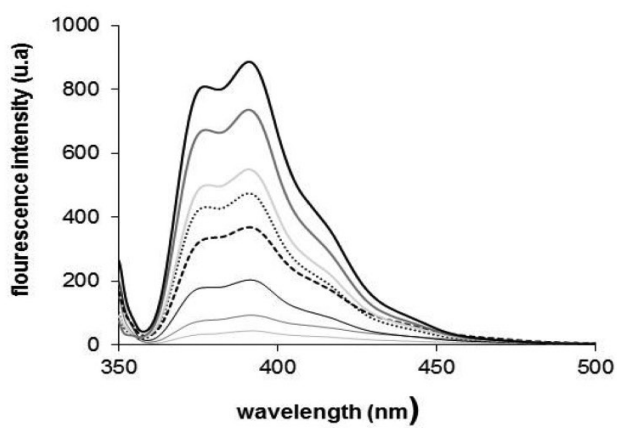

1-hydroxypyrene

(D)

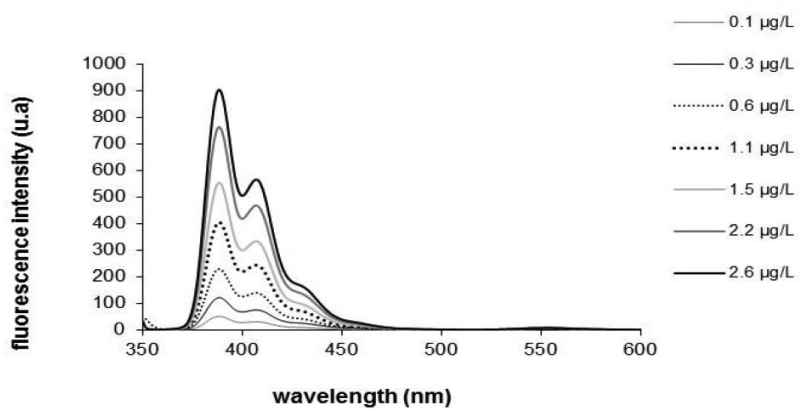

Figure 2. Fixed fluorescence $(F F)$ emission spectra for A. Naphthalene $\left(\lambda_{\text {exc }}=270 \mathrm{~nm}\right) ; \boldsymbol{B}$. Pyrene $\left(\lambda_{\text {exc }}=340 \mathrm{~nm}\right) ; \boldsymbol{C}$. Benzo $($ a $)$ pyrene $\left(\lambda_{\text {exc }}=380 \mathrm{~nm}\right)$ standard solutions and the synchronous fluorescence spectra of: $D .1$ - hydroxypyrene standard solution, $\Delta \lambda=37 \mathrm{~nm}$

Wavelength specificity evaluation

The specificity of the PAH standard metabolite determination for the previously chosen wavelengths by the standard addition method was also evaluated, in order to assess possible interferences from other investigated metabolites. The results indicate that the standard additions did not influence the determination of the other metabolites, with the exception of naphthalene (Figure 4).

The addition of both pyrene and benzo(a)pyrene led to a small increase in naphthalene fluorescence, due to the fact that pyrene and benzo(a)pyrene exhibit absorption at same excitation wavelength as 
Table 2. Equations of the line and correlation coefficient $\left(\mathrm{r}^{2}\right)$ of the four PAH standard curves. The $\mathrm{Y}$ value represents fluorescence intensity (u.a.) and the $\mathrm{X}$ value represents metabolites concentration $\left(\mu \mathrm{g} \mathrm{mL}^{-1}\right)$

\begin{tabular}{llc}
\hline PAH & Equation of the line & $\mathrm{r}^{2}$ \\
\hline Naphthalene & $\mathrm{y}=13.78 \mathrm{x}+40,123$ & 0.9991 \\
Pyrene & $\mathrm{y}=88.64 \mathrm{x}+17,653$ & 0.9968 \\
Benzo(a)pyrene & $\mathrm{y}=41.29 \mathrm{x}+18,528$ & 0.9912 \\
1-hydroxypyrene & $\mathrm{y}=343.24 \mathrm{x}+8,082$ & 0.9994 \\
\hline
\end{tabular}

naphthalene. Figure 4d indicates that the addition of 1-hydroxypyrene, contrary to the expected, not only increased the fluorescence band of this compound, but also that of pyrene and naphthalene. The observed pyrene fluorescence increase is due to the fact that the pyrene analysis conditions are also the ideal conditions for all pyrene metabolites. Pyrene addition, however, did not cause a significant increase in 1-hydroxypyrene fluorescence, emphasizing the robustness and adequacy of the SFS technique for determining pyrene's major metabolite. The increased naphthalene fluorescence due to addition of 1-hydroxypyrene is explained by the fact that the absorption spectrum of this compound presents a band both between 300 and $400 \mathrm{~nm}$, and absorption bands at lower wavelengths, including a band displaying maximum absorption at $270 \mathrm{~nm}$, the same excitation wavelength as naphthalene. ${ }^{46}$

Fish bile Fluorescence spectra by Fixed (FF) and Synchronous Fluorescence (SFS)

Figure 5 presents the bile fluorescence spectra determined in the appropriate conditions for naphthalene, pyrene, benzo(a)pyrene and 1-hidroxypirene metabolites.

Fish bile samples exposed to PAH usually comprise a complex mixture of PAH metabolites, and many display a significant degree of fluorescent property similarity. Thus, the capacity of FF and SFS

Standard addition of naphthalene

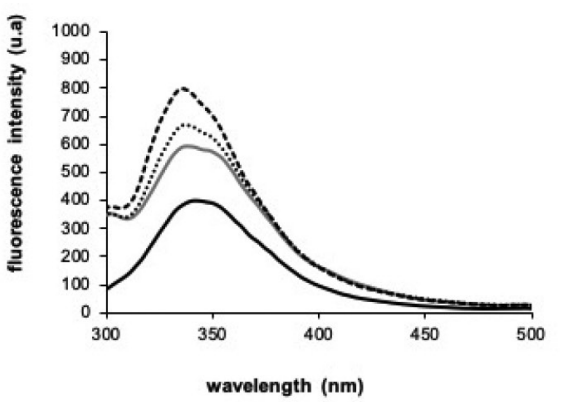

Standard addition of benzo(a)pyrene

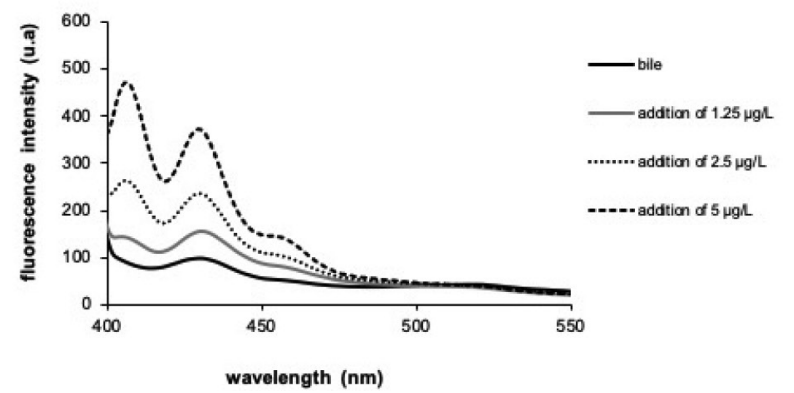

methods in distinguishing between the different PAH metabolites was assessed. While some fluorescence spectra overlap may occur in both methods, naphthalene, pyrene, benzo(a)pyrene and 1-hydroxypyrene were adequately identified. However, various PAHs and their metabolites may contribute to fluorescence in a single wavelength and, thus, absolute quantification of each of the investigated metabolites is not possible using the applied methods. Because of this, metabolite concentrations are considered semi-quantitative and are given as PAH-equivalents. ${ }^{27}$

On the other hand, FF is accurate and efficient in assessing fish exposure to different PAH metabolites, and adequate correlations between 1-hydroxypyrene determined in bile by SFS and by high performance liquid chromatography with fluorescence detection (HPLC-F) have been reported, with the latter considered a more specific method. ${ }^{43}$ Similarly, Lin (1996), demonstrated that naphthalene and benzo(a)pyrene metabolites can be determined via FF with good accuracy, ${ }^{38}$ and also reported satisfactory correlations between both methods. ${ }^{38}$

\section{Fish Biliary PAH Metabolite as Biomarker of Exposure}

Aquatic ecosystems and biota are increasingly threatened by the exposure to PAH derived from both urban and industrial sources, as many of these compounds display carcinogenic, mutagenic or genotoxic properties. Because of this, the U.S. Environmental Protection Agency (EPA) prioritizes the monitoring of $16 \mathrm{PAHs}$, including Naphthalene, Pyrene and Benzo (a) pyrene.

Due to their hydrophobic characteristics, these compounds may be concentrated in sediments at levels thousands of times higher than in the water column, causing particularly strong impacts on benthic and demersal organisms ${ }^{47}$ In this context, fish are particularly vulnerable to PAH contamination, and, due to their central role in the food chain, as well as their commercial importance, biomonitoring assessments regarding PAH exposure are paramount. ${ }^{9}$

Standard addition of pyrene

(B)

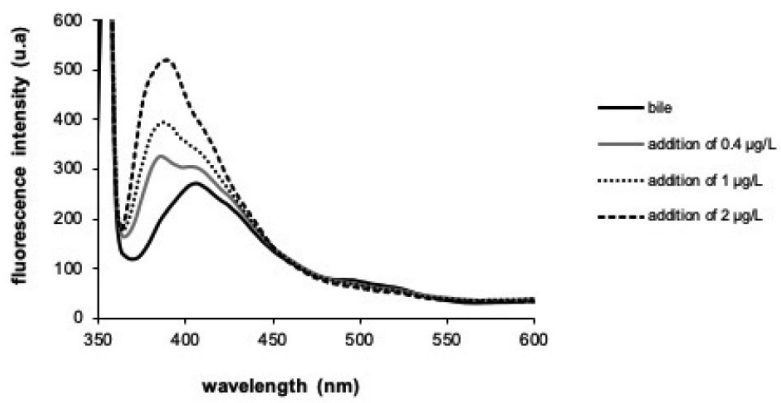

Standard addition of 1-hydroxypyrene

(D)

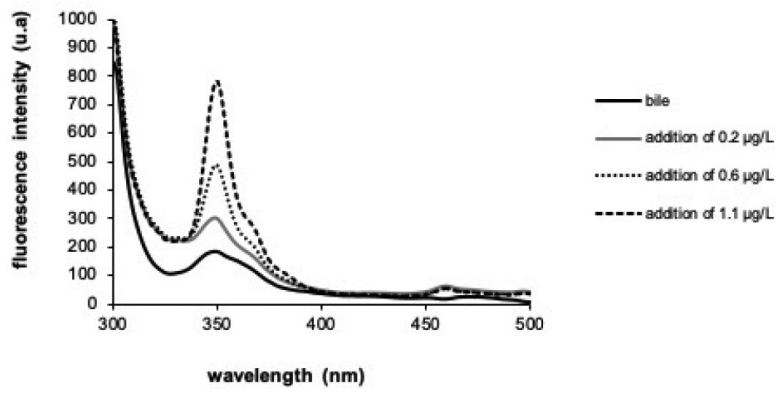

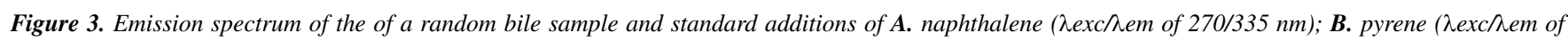
$340 / 390 \mathrm{~nm}) ; \boldsymbol{C}$. benzo(a)pyrene ( $\lambda$ exc $\lambda$ em of $380 / 430 \mathrm{~nm}) ; \boldsymbol{D} .1$ - hydroxypyrene $(\lambda=350 \mathrm{~nm} ; \Delta \lambda=37 \mathrm{~nm})$ to the same bile sample 
(A)

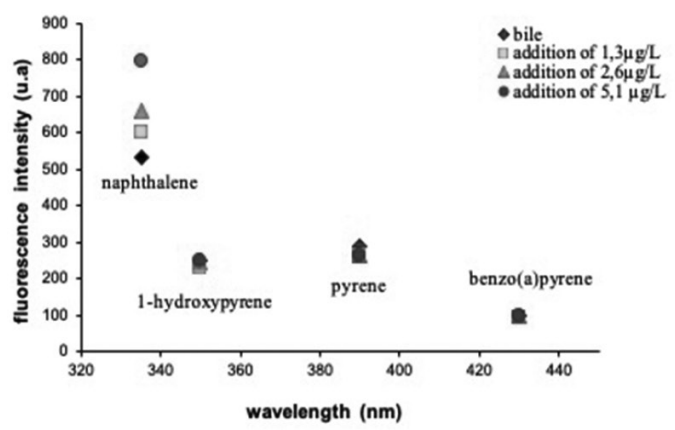

(C)

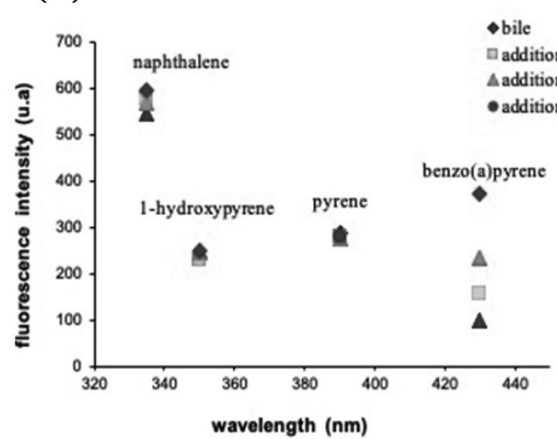

(B)

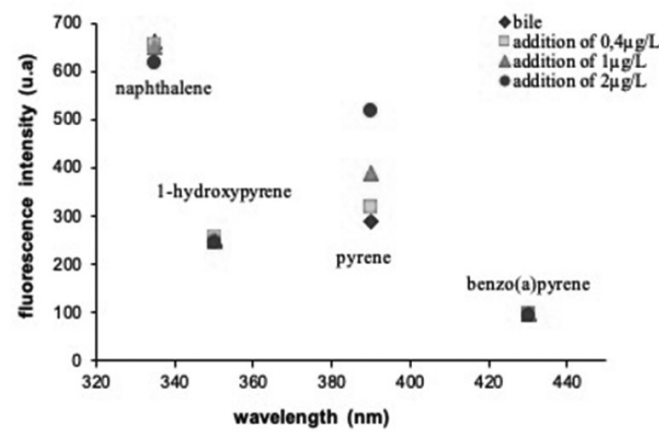

(D)

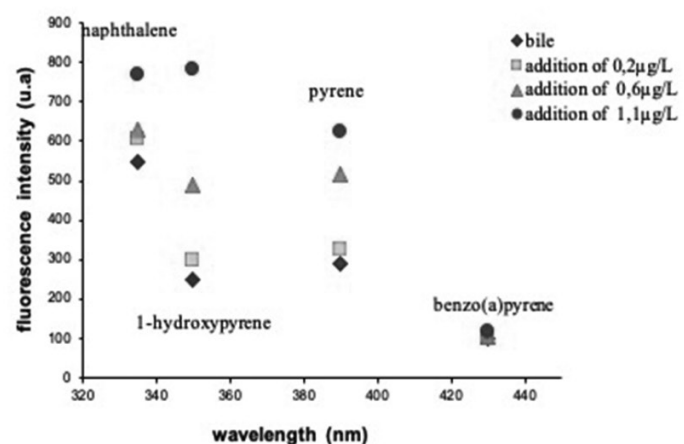

Figure 4. Measureaments at $\lambda_{e x c} \lambda_{e m}$ of 270/335, 340/390, 380/430 nm by FF, and at $\Delta \lambda=37 \mathrm{~nm}$ by FF of $\boldsymbol{A}$. naphthalene; B. pyrene; $\boldsymbol{C}$. benzo(a)pyrene and D. 1-hydroxypyrene standard additions
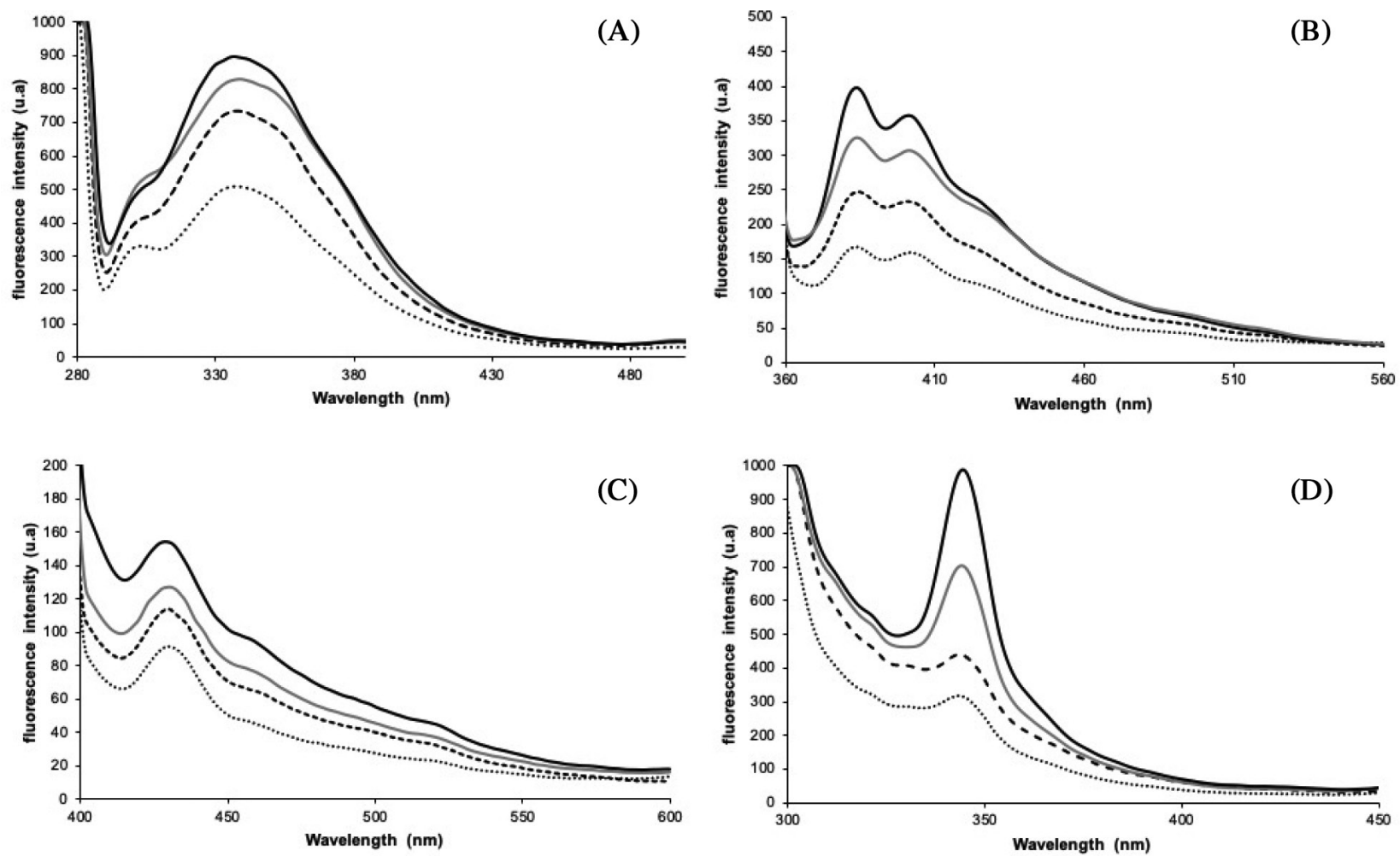

Figure 5. Fluorescence spectra of whitemouth croaker bile from Guanabara Bay and Itaipu analyzed by A. Fixed Fluorescence (FF) for naphthalene metabolites $\left(\lambda_{\text {exc }} \lambda_{\text {em }} 270 / 335 \mathrm{~nm}\right)$. B. Fixed Fluorescence $(F F)$ for pyrene metabolites $\left(\lambda_{\text {exc }} \lambda_{\text {em }} 340 / 390 \mathrm{~nm}\right)$. C. Fixed Fluorescence $(F F)$ for benzo(a)pyrene metabolites $\left(\lambda_{e x} \lambda_{e m}\right.$ of $\left.380 / 430 \mathrm{~nm}\right)$. D. Synchronous Fluorescence Spectroscopy (SFS) for 1-hydroxypyrene $\left(\Delta \lambda=37 \mathrm{~nm}, \lambda_{\text {em }} 350 \mathrm{~nm}\right)$

It is important to note that PAHs do not bioaccumulate for long periods of time in fish, nor are they biomagnified throughout the food chain, as they are easily metabolized by these animals. ${ }^{48}$
However, metabolization may result in potentially harmful reactive intermediates that can cause serious adverse effects. These effects can significantly alter fish populations and reach other populations that 
depend on these organisms as a food source. Indirect contamination effects in fish have been studied and competition among species for food and cascading trophic effects have been reported. Thus, the establishment of the homeostatic conditions of natural environments and biomonitoring efforts are required in order for adequate decisionmaking processes to be applied., ${ }^{9,49}$

However, monitoring and risk assessments of impacted environments cannot be based solely on the chemical analyses of environmental samples, since these assessments do not reflect deleterious effects caused by contaminants. ${ }^{23,50}$ Thus, biomarkers should be applied in order to assess the impacts of PAHs on environmental quality. ${ }^{24}$

Biliary PAH fluorescence determined through FF and SFS are appropriate concerning aquatic biota environmental quality monitoring studies. These methods are simple and present low costs, allowing for the assessment of a large number of samples and monitoring throughout time. In addition, they display high reproducibility and sensitivity, sufficient to distinguish between areas displaying different contamination degrees. ${ }^{10}$

The implementation and optimization of FF and SFS in the present study allowed for the semiquantitative determination of biliary Naphthalene, Pyrene, Benzo (a) pyrene and 1-hydroxypyrene metabolites in burrfish and croaker samples. The samples complete analysis was carried out in one year. Assessments concerning the selection of the best pairs of wavelengths and $\Delta \lambda$ were important to adapt these methods to the laboratorial conditions of CESTEH's Ecotoxicology Laboratory.

In addition, the methods allowed for the distinction between the different PAH metabolites and a semi-quantitative concentration determination. The results are consistent with other studies aimed at assessing PAH fish exposure through the same methodologies. ${ }^{27,30,34}$

The relative simplicity of both employed fluorescence methods enabled the assessment of a high number of specimens, decreasing the chance of biased results caused by biological variability.

\section{ACKNOWLEDGMENTS}

This article is dedicated to the memory of our friend and colleague Dr. A. S. Oliveira.

\section{REFERENCES}

1. Azevedo, L. A.; Brüning, I. M. R. de A.; Moreira, I.; Mar. Pollut. Bull. 2004, 49, 1109.

2. Christensen, J. H.; Tomasi, G.; de Lemos Scofield, A.; Meniconi, M. D. F. G.; Environ. Pollut. 2010, 158, 3290.

3. Fontana, L. F.; Crapez, M. A. C.; de Figueiredo Junior, A. G.; Santos, E. S.; da Silva, F. S.; Ribeiro, A. M.; Netto, A. D. P.; J. Coastal Res. 2012, $28,156$.

4. Barbosa, S. R. C. S.; Begossi, A.; Multiciência: arte e ciência 2004, 2,1 .

5. Vuorinen, P. J.; Keinänen, M.; Vuontisjärvi, H.; Baršiene, J.; Broeg, K.; Förlin, L.; Gercken, J.; Kopecka, J.; Köhler, A.; Parkkonen, J.; Pempkowiak, J.; Schiedek, D.; Mar. Pollut. Bull. 2006, 53, 479.

6. Silva, P.-V. M.; Buzitis, D. M. A.; Krahn, J.; Bícego, M. M.; Mar. Pollut. Bull. 2006, 52, 175.

7. Netto, A. D. P.; Moreira, J. C.; Dias, A. E. X. O.; Arbila, G.; Ferreira, L. F. V.; Oliveira, A. S.; Barek, J.; Quim. Nova 2000, 6, 765.

8. Mumtaz, M. M.; George, J. D.; Gold, K. W.; Cibulas, W.; Derosa, C. T.; Toxicol. Ind. Health 1996, 12, 742.

9. Logan, D.; Hum. Ecol. Risk Assess. 2007, 13, 302.

10. Ariese, F.; Beyer, J.; Jonsson, G.; Visa, C. P.; Krahn, M. M.; ICES Tech. Mar. Environ. Sci. 2005, 39, 41.
11. Howsam M.; Jones K. C.; In: PAHs and Related Compounds. The Handbook of Environmental Chemistry (Anthropogenic Compounds); Neilson, A. H., ed.; Springer: Berlin, Heidelberg, 1998, vol 3.

12. Olatubi, O. A.; Master's Thesis, Texas A\&M University, USA, 2005

13. Mackay, D.; Callcott, D.; In: Handbook of Environmental Chemistry, Neilson, A. H. eds; Springerlink, 1998.

14. Neves, R. L. S.; Master's Thesis, Pontifícia Universidade Católica do Rio de Janeiro, Brasil, 2006.

15. Beek, B.; Böhling, S.; Bruckmann, U.; Franke, C.; Jöhncke, U.; Studinger, G.; In: Handbook of Environmental Chemistry, Springerlink, 2000.

16. Bigler, J.; Greene, A.; Guidance for Assessing Chemical Contaminant Data for Use in Fish Advisories, Vol. 1. US EPA Office of Water, Office of Science and Technology, 1993.

17. Yamada, M.; Tanaka, H.; Toyoda, K.; Yoshida, A.; Shibata, A.; Nombra, H.; Mar. Pollut. Bull. 2003, 47, 105.

18. Collier, T.; Varanasi, U.; Arch. Environ. Contam. Toxicol. 1990, $20,462$.

19. Malins, D. C.; McCain, B. B.; Myers, M. S.; Brown, D. W.; Krahn, M. M.; Roubal, W. T; Schewe, M. H.; Landahl, J. T., Chan, S. L.; Environ. Health Perspect. 1987, 71, 5.

20. Landahl, J. T.; McCain, B. B.; Myers, M. S.; Rhodes, L. D.; Brown, D. W.; Environ. Health Perspect. 1990, 89, 195.

21. Yang, X.; Baumann, P. C.; Ecol. Indic. 2006, 6, 567.

22. Zitko, V; In: Handbook of Environmental Chemistry, Springerlink, 2000.

23. Barsiene, J.; Lehtonen, K. K.; Koehler, A.; Broeg, K.; Vuorinen, P. J.; Lang, T.; Pempkowiak, J.; Syvokiene, J.; Dedonyte, V.; Rybakovas, A.; Repecka, R.; Vuontisjärvi, H.; Kopecka, J.; Mar. Pollut. Bull. 2006, 53, 422.

24. Wells, P. G.; Depledge, M. H.; Butler, J. N.; Manock, J. J.; Knap, A. H.; Mar. Pollut. Bull. 2001, 42, 799.

25. Fuentes-Rios, D.; Orrego, R.; Rudolph, A.; Mendoza, G.; Gavilán, J. F.; Barra, R.; Chemosphere 2005, 61, 192.

26. Sarkar, A.; Ray, D.; Shrivastava, A. N.; Sarker, S.; Ecotoxicology 2006, $15,333$.

27. Aas, E.; Beyer, J.; Goks, A.; Biomarkers 2000, 5, 9.

28. Barra, R.; Sanchez-Hernandez, J. C.; Orreg, R.; Parra, O.; Gavilan, J. F.; Chemosphere 2001, 45, 438.

29 Dissanayake, A.; Galloway, T. S.; Mar. Environ. Res. 2004, 58, 281.

30. Aas, E.; Baussant, T.; Balk, L.; Liewenborg, B.; Andersen, O. K.; Aquat. Toxicol. 2000, 51, 241.

31. Oliva, M.; de Canales, M. L. G.; Gravato, C.; Guilhermino, L.; Perales, J. A.; Ecotoxicol. Environ. Saf. 2010, 73, 1842.

32. Czeslik, C. Z. Phys. Chem 2002, 216, 1137.

33. Gilbert, A.; Baggott, J.; Blackwell Scientific Publications, Oxford, Boston 1991: 302.

34. Beyer, J.; Jonsson, G.; Porte, C.; Krahn, M. M.; Ariese, F.; Environ. Toxicol. Pharmacol. 2010, 30, 224.

35. Suppan, P.; Chemistry and Light, Royal Society of Chemistry: Cambridge, UK, 2004.

36. Finete, V. L. M.; Master's Thesis, Pontifícia Universidade Católica do Rio de Janeiro, Brasil, 2005.

37. Krahn, M.; Burrows, D.; MacLeod, J. W.; Malins, D.; Arch. Environ. Contam. Toxicol. 1987, 16, 511.

38. Lin, E.; Cormier, S.; Torsella, J.; Ecotoxicol. Environ. Saf. 1996, 35, 16.

39. Ariese, F.; Burgers, I.; Oudhoff, K.; Rutten, T.; Stroomberg, G.; Vethaak, D.; Comparison of Analytical Approaches for PAH Metabolites in Fish Bile Samples for Marine and Estuarine Monitoring, Institute for Environmental Studies, Vrije Universiteit, Amsterdam, 1997.

40. Krahn, M.; Myers, M. S.; Burrows, D. G. Malins, D. C.; Xenobiótica 1984, 14, 633.

41. Vuontisjärvi, H.; Keinänen, M.; Vuorinen, P. J.; Peltonen, K.; Polycyclic Aromat. Compd. 2004, 24, 333.

42. Ariese, F.; Beyer, J.; Wells, D.; J. Environ. Monit. 2005, 7, 869. 
43. Ariese, F.; Kok, S. J.; Verkaik, M.; Gooijer, C.; Velthorst, N. H.; Hofstraat, J. W.; Aquat. Toxicol. 1993, 26, 273.

44. Yang, X.; Baumann, P. C.; Ecol. Indic. 2006, 6, 567.

45. Lima, A. L. C.; Master's Thesis, Pontifícia Universidade Católica do Rio de Janeiro, Brasil, 1996.

46. Berlman, I.; In: Handbook of Photochemistry, Academic Press, New York, 1971
47. Ruddock, P. J.; Bird, D. J.; McEvoy, J.; Peters, L. D.; Sci. Total Environ. 2003, 301, 105.

48. Miller, K. P.; Ramos, K. S.; Drug Metab. Rev. 2001, 33, 1.

49. Monserrat, J. M.; Martínez, P. E.; Geracitano, L. A.; Amado, L. L.; Martins, C. M.; Pinho, G. L.; Comp. Biochem. Physiol., Part C: Pharmacol., Toxicol. Endocrinol. 2007, 146, 221.

50. Cajaraville, M. P.; Bebianno, M. J.; Blasco, J.; Porte, C.; Sarasquete, C.; Viarengo, A.; Sci. Total Environ. 2000, 247, 295. 